\title{
вмJ Global Health COVID-19 vaccines pricing policy options for low-income and middle- income countries
}

\author{
Javier Guzman (D) , ${ }^{1}$ Tamara Hafner (D) , ${ }^{1}$ Lalla Arkia Maiga (D , ${ }^{1}$ Ursula Giedion ${ }^{2}$
}

To cite: Guzman J, Hafner T, Maiga LA, et al. COVID-19 vaccines pricing policy options for low-income and middle- income countries. BMJ Global Health 2021;6:e005347. doi:10.1136/ bmjgh-2021-005347

Received 10 February 2021 Revised 25 February 2021 Accepted 27 February 2021

A Check for updates

(C) Author(s) (or their employer(s)) 2021. Re-use permitted under CC BY-NC. No commercial re-use. See rights and permissions. Published by BMJ.

${ }^{1}$ USAID Medicines, Technologies, and Pharmaceutical Services (MTaPS) Program, Management Sciences for Health, Arlington, Virginia, USA

${ }^{2}$ Inter-American Development Bank, Washington, District of Columbia, USA

Correspondence to

Dr Javier Guzman;

jguzman@mtapsprogram.org

\section{INTRODUCTION}

Affordable and equitable access to medical products and technologies have long been a challenge for health systems. ${ }^{1}$ The COVID-19 pandemic has further highlighted this critical challenge, making it a priority agenda issue for countries globally. Prices drive health expenditure and ultimately population-wide coverage and access to novel products. For example, DIME, an Inter-American Development Bank-funded project, estimated that Costa Rica, Ecuador and Mexico would have to allocate five times their annual immunisation budgets to cover their high-risk populations if prices recently announced for two leading vaccine candidates in high-income countries were held for these three countries. ${ }^{1}$ The high prices increase the financial burden for populations and governments. ${ }^{2}$ As part of a broader policymaking process, one role for government is developing and implementing well-planned pricing policies and guidelines to help ensure affordable and equitable access. ${ }^{3}$ The COVID-19 pandemic, however, limits pricing policy options. It is therefore necessary to consider what appropriate policy options governments can use to ensure affordable and equitable access to these novel products.

\section{DRIVERS OF HIGH PRICES}

As of January 2021, nearly 200 vaccines were in development, several candidates have received emergency use authorisation and vaccinations have started. However, by most estimates, demand will continue to outstrip supply for the foreseeable future. ${ }^{2}{ }^{4}$ Manufacturing capacity is a rate-limiting factor and current models predict there will not be enough vaccine doses to cover the world's population until 2023 or $2024 .^{2}$ The limited supply means this is a supplier's market for the foreseeable future. Most low-income
Summary box

Commonly used policies such as fostering competition, generic substitution, and external and internal reference pricing will not work for novel vaccines.

- The rapid pace of vaccine development and the lack of historic safety, efficacy and pricing data make it difficult for governments to make informed procurement decisions to ensure equitable and affordable access.

- Transparent priority setting mechanisms for reviewing the evidence, measuring costs and benefits will be critical for evidence-based comparisons between vaccines, and between vaccines and other COVID-19 interventions.

- Low-income and middle-income countries and the donor community can leverage joint procurement mechanisms and voluntary or compulsory licensing agreements as policy options for equitable and affordable access.

- One potential target for advocacy is the deduction of government research and development subsidies for COVID-19 vaccine development.

- Low-income and middle-income countries lack adequate feasible pricing policies to ensure affordable and equitable access to the urgently needed vaccines being developed.

countries are excluded from the competition for doses because of their low purchasing power. Approximately 7.1 billion doses have already been purchased with high-income countries purchasing most doses. Countries like Canada and the UK have purchased approximately five doses per capita. ${ }^{24}$ Middleincome countries such as Brazil, India and Peru have leveraged their manufacturing or clinical testing capacity in negotiating purchase agreements. India is also developing several vaccine candidates and authorised its first COVID-19 vaccine, for emergency use. ${ }^{5}$ Some low-income countries have signed advanced purchase agreements, but none is expected to have enough to cover their population. To date, roughly 49 higher income 
countries have administered more than 39 million vaccine doses compared with only 25 doses in one lowest income country. ${ }^{6}$ A model by Northeastern University forecasted a $61 \%$ reduction in global COVID-19 mortality if the first 3 billion doses of vaccines are distributed proportionally by national population. This compares with only a $33 \%$ reduction if the first 2 billion doses are co-opted by high-income countries with the remaining 1 billion doses distributed equally globally. ${ }^{7}$

The purchase agreements are secret but the limited information available points to variation in prices and high price signals. ${ }^{8}$ The USA is estimated to be paying $\$ 19.50$ and the European Union $\$ 18.90$ per dose for the Pfizer/BioNTech vaccine. ${ }^{9}$ The US purchase price varies from $\$ 4$ per dose for the Oxford/AstraZeneca vaccine to $\$ 37$ per dose of the Moderna vaccine. ${ }^{8}$ Israel's willingness to pay a higher price, reportedly $\$ 30$ per dose for the Pfizer/BioNTech vaccine, has been cited along with its agreement to serve as a global pilot for vaccine rollout, as one reason for its rapid scale up of its vaccination programme. ${ }^{10}$ The secrecy of the agreements limits the negotiating power of low-income and middle-income countries with already limited purchasing power.

\section{ADDRESSING HIGH PRICES}

Innovative products require low-income and middleincome country governments to strike a delicate balance with their pricing policies-ensuring equitable, affordable and timely access to promising products, maximising value for money and securing the financial viability of their health systems. The challenge of striking that balance becomes even more acute in the context of the COVID-19 pandemic because of the urgency of the need, the supply scarcity and the lack of a strong evidence base to determine value, guide prioritisation and inform price negotiation. Typical pricing policies for innovative products such as external reference pricing will not work because of the lack of transparency and comparative, historic pricing data. Further, commonly used policies such as fostering competition, generic substitution and internal reference pricing do not apply to single-source products.

\section{Priority setting}

As more vaccines progress through the research and development $(\mathrm{R} \& \mathrm{D})$ process and manufacturers ramp up production, countries are likely to face a choice of products varying in price, efficacy, safety and overall product profile. The rapid pace of development and the lack of historic safety, efficacy and pricing data make it difficult for governments to make informed procurement decisions to ensure affordable prices, value for money and population-wide coverage. The situation calls for transparent, consistent priority setting mechanisms-reviewing the evidence, measuring costs and benefits, determining the budget impact implications of different coverage arrangements-so governments can make evidence-based comparisons between vaccines, and between vaccines and other COVID-19 interventions. Having clear priority setting mechanisms will help governments make transparent and consistent decisions about who gets vaccinated when and how for the immediate emergency response and serve as the basis for refining prioritisation and allocation decisions in the long term.

\section{Joint procurement mechanisms}

An immediate option for governments competing for access to potential COVID-19 vaccines is to join global and regional procurement mechanisms to increase purchasing power and reduce transaction costs. The COVAX facility aims 'to accelerate the development and manufacture of COVID-19 vaccines, and to guarantee fair and equitable access for every country in the world'. ${ }^{11}$ COVAX consists of 94 self-financing countries and 92 advance market commitment (AMC) countries. Other regional procurement mechanisms such as the Pan American Health Organization's Revolving Fund and the African medical supplies platform hosted within the Africa Centres for Disease Control and Prevention might also play an important role in aggregating demand and increasing the bargaining power of Latin American and African countries, respectively.

Two potential disadvantages of COVAX are the dependency on successful fundraising and the risk of some countries diluting the purchasing power with bilateral agreements. COVAX plans to cover $20 \%$ of the population in AMC countries, pending funding commitment. As of January 2021, it had secured 2 billion doses, with options on an additional 1 billion doses and deliveries expected to start February 2021. High-income countries have been prioritising bilateral agreements and circumventing the facility to be first in line for vaccines, raising concerns about the high price signals and threats to COVAX's coordinated response-undermining access for low-income and middle-income countries and reducing the purchasing power of the COVAX facility and any other regional procurement initiatives. ${ }^{2}{ }^{6}$ To further help ensure equitable access, the facility also developed a dose-sharing framework and has been urging highincome countries to contribute doses obtained through bilateral agreements. ${ }^{12} 13$

\section{Voluntary and compulsory licences}

Governments could also consider the use of compulsory or voluntary licensing agreements. Compulsory licensing is one of the flexibilities afforded by the TradeRelated Aspects of Intellectual Property Rights Agreement. Governments can issue a compulsory licence-if attempts to negotiate a voluntary licence fails-allowing manufacturers other than the patent owner to use the patent rights to make, use or otherwise trade a product for domestic use without the permission of the patent owner. In the case of a national emergency, governments can bypass the voluntary licensing process. Several countries used compulsory licences to lower the prices 
of antiretroviral medicines during the HIV/AIDS public health crisis. ${ }^{14}$

To use voluntary and compulsory licences for the current pandemic, countries need to have adequate legislative frameworks in place. Several countries including Canada, Chile and Ecuador have taken legal steps for using compulsory licences in their pandemic response. ${ }^{14}$ Costa Rica has proposed a global pooling mechanism with free access or licensing to COVID-19 technologies, a proposal supported by the WHO. ${ }^{15}$ The Medicines Patent Pool-a Unitaid-financed mechanism that pools patent licences for the production and supply of essential medicines-has also expanded its mandate to include COVID19-related medical products and technologies.

Besides the necessary legislative frameworks, countries also need to have the technical and manufacturing capacity. The WHO established the COVID-19 Technology Access Pool (C-TAP) to facilitate sharing of intellectual property, technical knowledge for large-scale vaccine production. Unfortunately, C-TAP remains empty despite official support from 41 countries. Some companies have been open to sharing their intellectual property. Moderna, for example, has agreed to waive its patent rights for those wishing to reverse engineer its vaccine. ${ }^{16}$

\section{Deduction of public subsidies}

One potential target for advocacy is the public subsidies invested in COVID-19 R\&D. Public and philanthropic funding for COVID-19-related R\&D is estimated at $\$ 3.3$ billion. ${ }^{17}$ The prospect that private companies stand to profit from public and philanthropic funding of their COVID-19-related R\&D pipeline has pushed experts to argue for companies' commitment to access and affordability as a condition for such funding. As part of its partnership agreement with partner University of Oxford, for example, AstraZeneca is participating in technology transfer with the Serum Institute in India. Several companies, including Pfizer, have signed on to the Bill and Melinda Gates Foundation's Global Access Communique committing to enabling affordability in lower income countries. Given the high level of public and philanthropic funding for COVID-19, donors and lower income country governments could pressure highincome countries to deduct government subsidies from product prices, which may help secure fair equitable prices for lower income countries.

\section{CONCLUSION}

The urgent need for COVID-19 vaccines coupled with the fast development pace means governments are acutely challenged to make evidence-based decisions to ensure affordable prices, efficacy and population-wide coverage. Low-income and middle-income countries face unique pricing challenges posed by innovative products in the context of an emergency response and lack of adequate feasible pricing policies to ensure affordable and equitable access to the urgently needed vaccines. This pandemic, by illustrating the importance of affordable medical products, provides an opportunity for countries to revisit pricing structures and policies for novel singlesource products.

Contributors All authors contributed equally to the conceptualisation and drafting of this manuscript.

Funding This study was funded by the US Agency for International Development (7200AA18C00074)

Competing interests None declared.

Patient consent for publication Not required.

Provenance and peer review Not commissioned; internally peer reviewed.

Data availability statement No data are available.

Open access This is an open access article distributed in accordance with the Creative Commons Attribution Non Commercial (CC BY-NC 4.0) license, which permits others to distribute, remix, adapt, build upon this work non-commercially, and license their derivative works on different terms, provided the original work is properly cited, appropriate credit is given, any changes made indicated, and the use is non-commercial. See: http://creativecommons.org/licenses/by-nc/4.0/.

\section{ORCID iDs}

Javier Guzman http://orcid.org/0000-0002-3013-0602

Tamara Hafner http://orcid.org/0000-0002-4710-0979

Lalla Arkia Maiga http://orcid.org/0000-0002-5733-8745

\section{REFERENCES}

1 Las metas de inmunización Y Los precios de las vacunas COVID-19 presionaránenexceso Los presupuestos de Los países de América Latina. Available: http://www.proyectodime.info/informacionregional/informacion-seleccionada-sobre-covid-19/boletines/lasmetas-de-inmunizacion-y-los-precios-de-las-vacunas-covid-19/ [Accessed 3 Feb 2021].

2 Duke Global Health Innovation Center. COVID-19 | Launch and scale Speedometer, 2020. Available: https://launchandscalefaster.org/ COVID-19 [Accessed 2 Nov 2020].

$3 \mathrm{WHO}$. Who guideline on country pharmaceutical pricing policies. Geneva, 2020. Available: https://www.who.int/publications/i/item/ 9789240011878 [Accessed 30 Nov 2020].

4 Callaway E. The unequal scramble for coronavirus vaccines - by the numbers. Nature 2020;584:506-7.

5 Corum J, Zimmer C. How Bharat Biotech's Covaxin Vaccine Works. New York Times, 2021. Available: https://www.nytimes.com/ interactive/2021/health/bharat-biotech-covid-19-vaccine.html?auth= login-email\&login=email [Accessed 19 Jan 2021].

6 WHO. WHO Director-General's opening remarks at 148th session of the Executive Board, 2021. Available: https://www.who.int/directorgeneral/speeches/detail/who-director-general-s-opening-remarksat-148th-session-of-the-executive-board [Accessed 19 Jan 2021].

7 Chinazzi M, Davis JT, Dean NE. Estimating the effect of cooperative versus uncooperative strategies of COVID-19 vaccine allocation: a modeling study. Available: https://www.mobs-lab.org/uploads/6/7/8/ 7/6787877/global_vax.pdf [Accessed 13 Dec 2020].

8 WSJ. Covid-19 vaccine makers signal prices. Available: https:// www.wsj.com/articles/covid-19-vaccine-makers-signal-prices11596648639 [Accessed 16 Nov 2020].

9 Banerjee A, Pfizer CHnaderV. U.S. strike 100 million COVID-19 vaccine deal with 70 milliondue by June. Reuters, 2020. Available: https://www.reuters.com/article/us-health-coronavirus-usa-pfizer/ pfizer-u-s-strike-100-million-covid-19-vaccine-deal-with-70-milliondue-by-june-idUSKBN28X1GC [Accessed 19 Jan 2021].

10 Regev D. The secrets to Israel's coronavirus vaccination success. Politico, 2021. Available: https://www.politico.eu/article/israelcoronavirus-vaccine-success-secret/ [Accessed 19 Jan 2021].

11 Over US\$ 2 billion raised to support equitable access to COVID vaccines with additional US\$ 5 billion needed in 2021 | Gavi, the Vaccine Alliance. Available: https://www.gavi.org/news/media-room/ over-us-2-billion-raised-support-equitable-access-covid-vaccinesadditional-us-5 [Accessed 16 Nov 2020].

12 COVAX. Principles for sharing COVID-19 vaccines doses with COVAX 2020.

13 World Health Organization. COVAX Announces additional deals to access promising COVID-19 vaccine candidates plans global rollout 
starting Q1 20212020 https://www.who.int/news/item/18-12-2020covax-announces-additional-deals-to-access-promising-covid-19vaccine-candidates-plans-global-rollout-starting-q1-2021

14 Wong $\mathrm{H}$. The case for compulsory licensing during COVID-19. J Glob Health 2020;10:010358.

15 Abbas MZ. Treatment of the novel COVID-19: why Costa Rica's proposal for the creation of a global pooling mechanism deserves serious consideration? J Law Biosci 2020;7:1-10.
16 McConaghie A. Pfizer and Moderna under pressure to offer vaccine supplies for developing nations. pink sheet. Informa pharma intelligence, 2020. Available: https://pink.pharmaintelligence. informa.com/PS143386/Pfizer-And-Moderna-Under- Pressure-ToOffer-Vaccine-Supplies-For-Developing-Nations [Accessed 13 Dec 2020].

17 Clinical Informatics Research Unit. Resin COVID-19. Available: https://www.the-ciru.com/resin-covid19 [Accessed 13 Dec 2020]. 